\title{
All hands on deck
}

\section{Recent moves by industry point to willingness to decarbonize the shipping sector, but greater coordination and} support is still needed.

n n October 2021, a collection of nine multinational companies that included Unilever, Ikea and Amazon, pledged to use only zero-emission ships to transport their cargo by 2040. The announcement came just months after Maersk-one of the largest shipping companies in the world-declared that they were ordering eight large containerships that can run on green methanol. The ships will replace older vessels powered by heavy fuel oil-a tar-like material that is the standard fuel in the industry-and therefore lower $\mathrm{CO}_{2}$ emissions. Taken together, this news demonstrates an important step by freight customers and suppliers alike in an industry renowned for being difficult to decarbonize.

This difficulty is in no small part due to challenges including the industry's global nature, the individuality of each vessel and the enormous energy needs resulting from the vast distances covered. In particular, the latter means that replacing the energy-dense heavy fuel oil with batteries is not feasible in many cases and instead some form of low-carbon fuel is required.

Still, most other low-carbon fuels have lower energy densities than heavy fuel oil and so switching one for the other has consequences for the amount of cargo that the additional fuel may displace. Alternative propulsion systems (such as fuel cells combined with electric motors), which have different volumetric and gravimetric implications, may also be necessary. To address this, researchers have sought to estimate how a change in fuel would influence the cargo-carrying capacity of individual reference ships. However, studies do not always take into account the wide variety of ship designs that exist and their patterns of operation. To decarbonize the whole sector, a deeper understanding of the potential for alternative fuels to power whole fleets is needed.

In an Analysis in this issue of Nature Energy, Boris Stolz, Maximilian Held and colleagues assess the techno-economic suitability of a number of alternative fuels produced from renewable electricity to power ships carrying bulk cargo in Europe. The researchers use real-world emission reports and tracking data to derive the voyages undertaken, weight of cargo carried and fuel consumed by individual ships in 2018. They then model how changing the fuel and propulsion systems of these ships changes their ability to carry the same weight of cargo over the same distances. Stolz et al. find that ammonia and methanol appear especially suitable fuels, in each case allowing over $90 \%$ of current cargo operations to continue as they are. To still be able to move all cargo, they suggest that various approaches could be taken such as adding refuelling stops or accepting reduced cargo capacity and increasing ship numbers.

It is perhaps no surprise that switching fuels comes at a price. Heavy fuel oil, being essentially what's left after high quality hydrocarbons have been removed from crude oil, is relatively cheap, so exchanging it for fuels made from electrolysis-derived hydrogen and $\mathrm{CO}_{2}$ captured from the air will of course increase costs of ship ownership: between 2-6 times according to Stolz et al. Additionally, the uncertainty around the magnitude of this increase-and how costs are passed on to the end-customer-can be daunting for those considering a switch to renewable fuels. Research is therefore still necessary to decrease this uncertainty and encourage early adopters.

Costs could be reduced by efficiency gains using strategies such as slow steaming, where a ship's speed is deliberately reduced in order to lower fuel consumption, harnessing of wind power and other design efficiencies, as well as shrewder voyage planning. These kinds of approaches could partly compensate for additional fuel costs. However, further study is needed to understand exactly how they intersect with changes in the main fuel used.

Nevertheless, some form of policy support will be required to close the gap between fossil fuels and cleaner alternatives. This could take the form of carbon levies and incentives to switch to zero-carbon fuels. At the same time, scale matters: support is needed at local and regional levels for ports and infrastructure, and at the global level to avoid a patchwork of national measures with conflicting stipulations and goals.

In that regard, the Clydebank Declaration for Green Shipping Corridors at COP26 is encouraging. The plan is to create at least six zero-emission maritime routes between two or more ports by 2025 . This will be achieved by establishing partnerships between ports, operators and others along the value chain with a focus on actions to facilitate decarbonization through introduction of regulatory frameworks, incentives and green infrastructure. Elsewhere, a green corridor between the ports of Shanghai and Los Angeles is being worked on that aims to introduce the world's first zero-carbon trans-Pacific container ship by 2030 .

These developments suggest a willingness for individual countries and ports to collaborate and decarbonize regardless of a perceived lack of ambition from the International Maritime Organisation (IMO), shipping's United Nations regulator. Indeed, the IMO has come in for criticism from UN Secretary-General António Guterres for pursuing only a $50 \%$ reduction in annual greenhouse gas emissions from the sector by 2050 relative to 2008 levels, which he feels is more in line with an above $-3^{\circ} \mathrm{C}$ warming scenario than a $1.5^{\circ} \mathrm{C}$ scenario. Nonetheless, proposals to target net-zero emissions by 2050 were rejected late last year by the IMO's member states, leaving it largely to individual companies and ports, rather than global regulation, to drive decarbonization for now.

The shipping sector is responsible for around 2-3\% of annual greenhouse gas emissions, and its share of emissions is predicted to increase enormously in the coming decades without intervention. Pledges from retailers to commit to zero-carbon shipping put pressure on shipping companies to act, while announcements from shipping companies to use green fuels are important signals to fuel producers that a market exists. Scaling these fuels is a pressing need; in their announcement, Maersk admitted that sourcing enough green methanol on day one of the ships' service will be difficult. Furthermore, considering the lifetime of ocean-going vessels, the fleet we plan today will be with us for decades. Our choices now will directly influence the trajectory of emissions in the shipping sector for years to come. There is no time to waste.

Published online: 25 February 2022 https://doi.org/10.1038/s41560-022-00995-X 